\title{
Characterization of Live and Experimentally Degenerated Hyaline Cartilage with Thermal Analysis
}

\author{
Gellért Sohár ${ }^{1}$, Piroska Szabó-Révész², Kálmán Tóth ${ }^{1}$ and Zoltán Aigner ${ }^{2}$ \\ ${ }^{1}$ Department of Orthopaedics, University of Szeged, Faculty of Medicine, Szeged, \\ ${ }^{2}$ Department of Pharmaceutical Technology, University of Szeged, \\ Faculty of Pharmacy, Szeged, \\ Hungary
}

\section{Introduction}

Osteoarthritis (OA), the most prevalent joint disease, is characterized by the progressive loss of articular cartilage that leads to chronic pain and functional restrictions in affected joints [Goldring \& Goldring, 2007]. The prior notion of OA as a bland disease related to aging and "wear and tear" of the joint has given way to views of a dynamic system with multiple pathogenic contributors, as local factors, as well as crystals and inflammation [Brandt et al., 2006]. OA represents a major therapeutic challenge to medical and health-care providers. In part, this is because OA is a chronic condition in which symptoms evolve over long periods of time and in which symptomatic episodes are frequently separated by lengthy asymptomatic periods. It is likely, however, that alterations in joint structure and function continue during these relative periods of clinical quiescence. In addition, limited tools are available for the assessment of the progression of structural changes in joint tissues in association with the development of osteoarthritis. Importantly, the correlation between structural alterations and symptoms is contradictory. There is a significant difference in the expression levels of cartilage relevant molecules between specimens showing histological alterations and control samples [Lorenz et al., 2006]. A total breakdown in synthesis of matrix molecules leads to the end stage OA with further progression of cartilage loss.

A number of OA models, e.g. aging animals, genetically modified mice, as well as animals with surgically, enzymatically, or chemically induced OA [van den Berg, 2001] have been developed to investigate the pathogenesis of $\mathrm{OA}$ and evaluate the potentials of new disease/structure-modifying drugs [Oegema et al., 2002]. Among these, monosodium iodoacetate (MIA, iodoacetic acid) model has been widely used to analyze the histological and biochemical changes observed during the progression of OA [Ameye, \& Young, 2006]. Injection of the metabolic inhibitor, MIA, into joints inhibits glyceraldehye-3-phosphate dehydrogenase activity in chondrocytes, resulting in disruption of glycolysis and eventual cell death [Kalbhen, 1987]. The progressive loss of chondrocytes results in histologic and morphologic changes to the articular cartilage, closely resembling those seen in human OA [Janusz et al., 2001]. In addition, the model has been utilized by a number of investigators to test pharmacologic agents for their ability to preserve cartilage structure [Janusz et al., 2001]. 
Glucosamine, a naturally-occurring amino monosaccharide, is present in the polysaccharides of the connective and cartilage tissues, and contributes to maintaining the strength, flexibility, and elasticity of these tissues. Thus, glucosamine has been widely used for more than two decades in humans to treat osteoarthritis [Crolle, 1980]. Several short- and long-term clinical trials in osteoarthritis have shown the significant symptom-modifying effect of glucosamine [Reginster, et al., 2001]. Moreover, the updated Osteoarthritis Research Society International (OARSI) recommendations for management of hip and knee OA have recently suggested that glucosamine has symptom-relieving and structure modifying effects in knee OA [Zhang et al. 2008]. Importantly, it has been previously revealed in vitro that glucosamine can inhibit the degradation and stimulate the synthesis of glycosaminoglycans (proteoglycans), thereby possibly exhibiting chondroprotective action [Fenton et al., 2000]. Moreover, glucosamine has been shown to reduce radiographic progression of joint space narrowing in knee OA [Reginster, et al., 2001]. On the other hand, Glucosamine/chondroitin Arthritis Intervention Trial reported that glucosamine did not reduce pain effectively in patients with OA [Clegg et al., 2006], and the nonsufficient number of trials cannot confirm statistically that glucosamine sulphite has no effect [Vlad et al., 2007]. Thus, the effect of glucosamine on OA is still controversial [McAlindon, 2003].

Thermal analysis comprises a group of techniques in which a physical property of a substance is measured as a function of temperature, while the substance is subjected to a controlled temperature programme. Differential scanning calorimetry (DSC) has been widely used for determining physicochemical transformations that occur during thermal degradation [Collett \& Brown, 1998]. Calorimetry can be used to determine most thermodynamic properties; e.g. enthalpy changes for reactions $(\Delta \mathrm{H})$ and for phase changes [Aigner et al., 2009; Than \& Lórinczy, 2003]. The usefulness of calorimetric examination in the characterization of biological samples has been demonstrated by previous studies [Than et al., 2000; Wiegand et al., 2009]. Prior studies have demonstrated the usefulness of calorimetric examination in the characterization of cartilage degeneration [Wiegand et al., 2010]. We have extended the use of thermal analysis by introducing thermogravimetric investigations. Thereby new information on the physicochemical properties of normal and OA tissues has been acquired.

An increasing number of papers have been published with the use of calorimetric techniques in the examination of degenerative [Mécs et al., 2009], rheumatoid arthritis [Tóth et al., 2009], and healthy human hyaline cartilage [Aigner et al., 2009]. P. Than et al. investigated first animal hyaline cartilage using differential scanning calorimetric method [Than et al., 2000]. They have concluded that structural manifestation of OA causes a remarkable change of thermal stability of hyaline cartilage. The healthy cartilage samples used in these studies were of cadaver origin as waste material, pathological cartilage was derived as intraoperative tissue fragments. The samples were washed in sterile phosphatebuffered saline and stored in complex solution containing fetal bovine serum, antibiotic, antimycotic solution, and amino acids. The measurements were conducted in 48 hours of sample deriving. The reported data on the calorimetric enthalpy changes proved to be inconsistent. In severely affected osteoarthritis, the $\Delta H$ has increased almost twofold, while in an earlier study, enthalpy changes in the intact hyaline cartilage altered from higher to lower levels in some cases [Than et al., 2000; Than et al., 2004].

The aim of these studies was to further characterize the altered metabolisms in OA that promotes disease progression. Based on previous studies, we hypothesized that 
thermodynamic findings may clearly differentiate normal and degenerated human hyaline 'cartilage. Physicochemical transformations may provide information on the role of water content in OA, and enthalpy change of the process, initiated by the temperature change, might represent potential marker of the disease activity. Under experimental circumstances, calorimetric examinations were used to differentiate normal and degenerated rat hyaline cartilage and the effect of oral glucosamine-sulphate pre-treatment in OA was also studied. The purpose of this study was to elucidate complex deviations that are developed from the normal matrix composition during $\mathrm{OA}$ and $\mathrm{OA}$ with glucosamine-sulphate treatment in contributing to disease progression.

\section{Conceptual background}

\subsection{Pathology}

Articular cartilage has been the focus of research into OA for decades and the literature is extensive. The role of the chondrocytes has been reviewed [Hunziker, 2002], and some key features are also briefly summarized. The mechanical properties of cartilage, including viscoelasticity and high resistance against load and shear stress, are controlled through the metabolic balance within the matrix collagen-proteoglycan network. Water is the main composite $(60-80 \%)$ of the extracellular matrix [Armstrong \& Mow, 1982; Mankin \& Thrasher, 1975; Sandell \& Hering, 2001]. Proteoglycans induce a high osmotic pressure and have a high water binding capacity. Between 5 and $10 \%$ of the cartilage mass are proteoglycans, mostly aggrecan [Eyre, 2002]. Collagen (90\% collagen type II) is responsible for the high resistance against tensional forces. Collagen type II contributes to up to $60 \%$ of the dry weight [Mayne, 1989]. During inflammation or slow degeneration, the homeostasis within the collagen-proteoglycan network in the chondral matrix is disordered [Sandell \& Hering, 2001].

Theoretical and computational analyses of the contact response of cartilage under various loading conditions have predicted that more than $90 \%$ of the load transmitted across articular layers is supported by the pressurized interstitial fluid, with the remnant contributed by the collagen-proteoglycan solid matrix. Since the pressure of this fluid is a hydrostatic stress, and since cartilage has been shown to be nearly incompressible at physiological levels of pressures, it has become evident that the interstitial fluid shields the solid matrix from excessive deformations [Park et al., 2003; Soltz \& Ateshian, 1998].

\subsection{Thermal analysis}

Thermal analysis comprises a group of techniques in which a physical property of a substance measured as a function of temperature, while the substance is subjected to a controlled temperature programme. Differential scanning calorimetry (DSC) and thermogravimetric (TG) analysis have been widely used for determining physicochemical transformations that occur during thermal degradation [Bihari-Varga 1982; Collett \& Brown, 1998]. These techniques measure net changes in enthalpy and weight as a result of many reactions taking place simultaneously and are particularly useful for indicating the temperature range and the rate of thermal processes as well as giving considerable information on physical and chemical changes [O'Neill, 1964; Richardson, 1997]. Not many papers have been published on the thermal properties of human hyaline cartilage. 
Understanding the response of drugs and their formulations to thermal stresses is an integral part of the development of stable medicinal products. Thermal analytical methods have thus become important tools for the development of modern medicines. These are precise and accurate techniques with low sample requirements, and can provide detailed information about new chemical entities even at the very earliest stages of drug discovery and development [Clas et al., 1999].

\subsubsection{Thermogravimetry}

Thermogravimetric analysis (TGA) is an analytical technique used to determine a material's thermal stability and its fraction of volatile components by monitoring the weight change that occurs as a specimen is heated [Gill, 1992]. The measurement is normally carried out in air or in an inert atmosphere, such as Argon, and the mass is recorded as a function of increasing temperature. Sometimes, the measurement is performed in a lean oxygen atmosphere ( 1 to $5 \% \mathrm{O}_{2}$ in $\mathrm{N}_{2}$ or $\mathrm{He}$ ) to slow down oxidation. In addition to mass changes, some instruments also record the temperature difference between the specimen and one or more reference pans (differential thermal analysis, or DTA) or the heat flow into the specimen pan compared to that of the reference pan (differential scanning calorimetry, or DSC). The latter can be used to monitor the energy released or absorbed via chemical reactions during the heating process.

In most cases, TG analysis is performed in an oxidative atmosphere (air or oxygen and inert gas mixtures) with a linear temperature ramp. The maximum temperature is selected so that the specimen mass is stable at the end of the experiment, implying that all chemical reactions are completed (i.e., all of the carbon is burnt off leaving behind metal oxides). This approach provides two important numerical informations: ash content (residual mass, $\mathrm{M}_{\text {res}}$ ) and oxidation temperature $\left(\mathrm{T}_{\mathrm{o}}\right)$. While the definition of ash content is unambiguous, oxidation temperature can be defined in many ways, including the temperature of the maximum in the weight loss rate $\left(\mathrm{dm} / \mathrm{dT}_{\max }\right)$ and the weight loss onset temperature $\left(\mathrm{T}_{\text {onset }}\right)$. The former refers to the temperature of the maximum rate of oxidation, while the latter refers to the temperature when oxidation just begins. The ability of TG to generate fundamental quantitative data from almost any class of materials, has led to its widespread use in every field of science and technology [Riesen, 1998; Rouquerol, 1989].

\subsubsection{Calorimetry}

Differential scanning calorimetry (DSC) is a thermoanalytical technique for measuring the energy necessary to establish a nearly zero temperature difference between a substance and an inert reference material, as the two specimens are subjected to identical temperature regimes in an environment heated or cooled at a controlled rate. In heat-flux DSC, the sample and reference are connected by a low-resistance heat-flow path (a metal disc). The assembly is enclosed in a single furnace (Fig. 1).

Enthalpy or heat capacity changes in the sample cause a difference in its temperature relative to the reference; the resulting heat flow is small as compared to that of in differential thermal analysis (DTA) because the sample and reference are in good thermal contact. The temperature difference is recorded and related to enthalpy change in the sample using calibration experiments [O'Neill, 1964].

DSC is a frequently preferred thermal analytical technique because of its ability to provide detailed information about both the physical and energetic properties of a substance. This 
information cannot be obtained accurately, easily, or quickly using any other technique. With the development of sophisticated, modulated temperature programs, it is likely that DSC will retain its place at the forefront of the pharmaceutical thermal analytical sciences for some time to come [Clas et al., 1999].

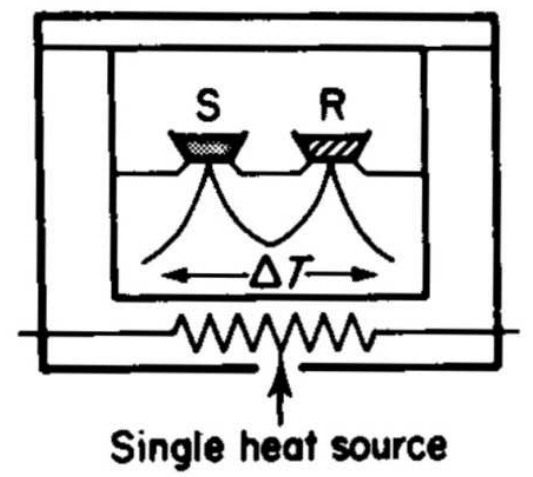

Fig. 1. Heat flux DSC (S: substance, R: reference material)

Calorimetry can be used to determine most thermodynamic properties; e.g. enthalpy changes for reactions $(\Delta \mathrm{H})$ or phase changes. Calorimetry can also be used for qualitative and quantitative analyses. $\Delta \mathrm{H}$ can often be determined for an unknown reaction in a complex system, and the value of $\Delta \mathrm{H}$ can then be used to assist in identifying the reaction [Jones, 1997]. Since calorimetry directly measures the instantaneous rate of the process, calorimetry is a particularly advantageous method for determination of the kinetics of slow processes. Calorimetric parameters provide a description of the system as a function of the experimental variables. Calorimetric data can also be used to gain fundamental insight into a process or property of a material [Hansen \& Russell, 2006].

\subsection{Thermal analysis of biological systems}

Biological samples are often expensive and scarce due to the difficulty of their isolation and purification [Collett \& Brown, 1998; Privalovand \& Plotnikov, 1989]. The biological system represents an aqueous environment and the water present in the specimen limits the amount of sample that can be investigated, when studying the bulk properties of a sample. Analysis of the conformational and structural changes of molecules requires the solutions to be sufficiently dilute so that the inter-molecular contributions can be ignored. Advantages of thermal analysis in biological studies: the thermal behavior of tissues, as opposed to tissue components, can be readily studied by thermal analysis. No preparation procedures are required and so the basic molecular structures can be preserved for the analysis [Burroughs et al., 1980]. Initially, thermal transitions were only used to gain insight into the structures of compounds, but subsequently, applications have also been extended to give physiological data [Collett \& Brown, 1998; Melchior \& Steim, 1976]. These interactions are probably best studied by thermodynamic methods. Of all the thermal analysis techniques applied to biological samples, DSC and TGA are the most commonly used. These applications of thermal analysis to the study of biological systems have obvious medical advantages [Melchior \& Steim, 1976]. 


\subsection{Thermal analysis of connective tissue}

Connective tissue may be classified as a semifluid gel in order to explain its properties and functions. Thermal analysis of the material requires no preparation procedures. The material could thus be studied without complicated purification procedures which means that the basic molecular structure can be preserved [Bihari-Varga, 1982]. Bihari-Varga concluded that connective tissue, like other tissue, shows considerable changes as the body passes to older age, and that, it is affected by pathological conditions. The study revealed that both the amount of structurally bound water and the concentration of glycosaminoglycan's (GAG) decrease significantly with age in various types of connective tissues.

More than 35 years ago in Bihari-Varga's experiments [Bihari-Varga et al., 1975] complex thermoanalytical methods [Paulik et al., 1958] were applied to study various collagenproteoglycan-glycoprotein complexes prepared from different connective tissues. Thermal analysis was successfully used in their investigations for the quantitative determination of polysaccharides, for the characterization of protein structure, and for the estimation of agerelated [Simon et al., 1969] and pathological [Biró \& Bihari-Varga, 1972] changes in proteoglycan- and collagen-containing biological tissues. The study was extended to investigate the effect of drugs on the osteoarthritic tissue [Farkas et al., 1974].

More recently, thermal stability and structure of cancellous bone mineral from the femoral head of patients with OA or osteoporosis (OP) was investigated by Mkukuma et al. [Mkukuma et al. 2005]. Thermogravimetric analysis was linked to mass spectrometry (MS) to investigate the thermal decomposition of the matrix and hence its mineral content. Thermal stability of the bone matrix or the mineral phase alone, was little altered by disease, though OA bone contained less mineral than OP or control normal bone [Mkukuma et al. 2005].

\subsection{Cartilage water content}

Simple collagen-water systems have been examined with nuclear magnetic resonance (NMR) spectroscopy. It was shown that water molecules exist either as bulk water or as interior hydration water molecules [Chae et al., 2009]. Water within collagen fibrils consists of molecules involved in both inter- and intrahelical hydrogen bond formation. Based on a single endothermic DSC peak in cartilage, Bagratashvili et al. [Bagratashvili et al. 1997] found that the proportion of bound water in cartilage is around $4 \%$ using differential microcalorimetry and FTIR spectroscopy. Water diffusion through the tissue and from bound to free water transformation controlled water molecule liberation and adsorption. Alternating breakage and reformation of weak bonds between water molecules and proteoglycans directs movement of water in cartilage tissue. Both the extrafibrillar and most of the intrafibrillar water is freely exchangeable and behaves towards small solutes as available water has been independently shown by Katz and $\mathrm{Li}$ [Katz \& Li, 1973] for other collagenous tissues. Furthermore Maroudas and Schneiderman have shown that the very major fraction of cartilage water is free, therefore the water in cartilage is completely exchangeable under a variety of experimental conditions [Maroudas \& Schneiderman, 1987].

\section{Experimental}

\subsection{Materials}

\subsubsection{Patients}

In order to conduct the thermoanalytical study, 23 samples were collected from live surgeries of OA patients between October 2005 and April 2006. During hip arthroplasty 
procedures performed at the Orthopedic Department, University of Szeged, 16 OA human hyaline cartilage samples and normal cartilage from 7 knee were obtained. There was no clinical meaningful difference in age between OA patients $(64 \pm 5.2)$ and controls $(61 \pm 4.2)$. There were no considerable sex differences between OA patients (75\% females) and controls (70\% females); Chi-square $\mathrm{P}=0.54$.

Usually, total knee arthroplasty is performed in OA of both medial and lateral knee compartments. When only one compartment is affected and ligamental stability is intact, unicondylar prosthesis is implanted. We were able to obtain normal cartilage samples from those patients where one compartment of the same knee was degenerated, and the other one was normal. Therefore, the unaffected femoral condyle had to be sacrificed for the procedure because ligamental instability was the indication for total knee arthroplasty.

\subsubsection{Patients grading}

Preoperatively, the diagnosis of the patients were established on the basis of the patient history, clinical signs, laboratory tests, and radiological findings. The state of the hyaline cartilage was determined intraoperatively. All patients in the osteoarthritic group were considered to be 5-6 articular surface degeneration by Osteoarthritis Research Society International (OARSI) grade. OARSI Grade 5-6 OA is characterized by deformation and change in the contour of the articular surface [Pritzker et al., 2006]. This results not only from articular plate fractures, but also from increased metabolic activity of the articular bone plate, as well as from activation of connective tissue at the lateral and, sometimes, central cartilage/bone interfaces. Samples were considered to be normal when hyaline articular cartilage was uninvolved with OA (OARSI Grade 0). In these results, the cartilage surface is smooth, no enlargement, distortion, and no proliferative changes are observed.

\subsubsection{Human sample preparation for thermal analysis}

After the operation, a disc ( $5 \mathrm{~mm}$ in diameter) was removed from the unhealthy and healthy cartilage surfaces. The samples were taken under sterile conditions, excess bone was removed, and only the remaining full thickness cartilage was used. The disc was first washed in sterile saline, then stored in $20 \mathrm{ml}$ saline for transportation at room temperature. Mean storage time was 6 hours (min: 1 hour, max: 26 hour), 29 samples out of 35 were studied within four hours of preparation. Six samples were stored overnight at $5{ }^{\circ} \mathrm{C}$. Preemptive control examinations did not show any change in the calorimetric and thermogravimetric properties after storage for 26 hours at $5{ }^{\circ} \mathrm{C}$.

\subsubsection{Animal model}

Animal experiments were performed at the Physiology Department, Faculty of Medicine, University of Szeged. Adult male Wistar rats (Charles River strain; Bioplan, Budapest, Hungary), weighing $470 \pm 6 \mathrm{~g}$ were housed individually in ventilated cages on a 12-hour day/night cycle at a temperature of $22 \pm 1{ }^{\circ} \mathrm{C}$. Water and food were provided ad libitum. The experiments were performed in accordance with the US National Institutes of Health Guidelines for the Care and Use of Laboratory Animals, and with the approval of the Animal Welfare Committee of the University of Szeged. Four groups of animals were defined as follows:

GA, non-osteoarthritic negative control rats injected with saline but pre-treated with oral glucosamine-sulphate; 
Sham, non-osteoarthritic negative control rats injected with saline and not pre-treated with oral glucosamine-sulphate;

MIA, rats injected with monosodium iodioacetate and not pretreated with oral glucosaminesulphate;

MIA+GA, rats injected with monosodium iodoacetate but pretreated with oral glucosaminesulphate.

\subsubsection{Compounds}

Monosodium iodoacetate was obtained from Sigma-Aldrich Kft. Budapest and dissolved in $0.9 \% \mathrm{NaCl}$ (Baxter) solution to get the required concentrations.

Glucosamine sulphate was supplied by Rottapharm S.p.A., Italy.

\subsubsection{Induction of osteoarthritis}

Animals were briefly anesthetized with an isoflurane/O2 gas mixture and the left knee was shaved and disinfected with $70 \%$ ethanol followed by povidone-iodide. Osteoarthritis was induced by the intraarticular injection of $50 \mu \mathrm{l}$ of $40 \mathrm{mg} / \mathrm{ml}$ monosodium iodoacetate solution using a $300 \mu \mathrm{l}$ syringe fitted with a $29 \mathrm{G}$ needle, as described earlier [Guingamp et al., 1997]. The animals of the GA and Sham groups underwent the same procedure, but were injected with $50 \mu \mathrm{l}$ of $0.9 \% \mathrm{NaCl}$ solution.

\subsubsection{Glucosamine-sulphate pre-treatment}

Glucosamine sulphate solution dissolved in distilled water was administered to the rat through a cannula daily for 8 weeks through a gastric tube $(500 \mathrm{mg} / \mathrm{kg}$ dose per day in $2 \mathrm{ml}$ volume). The control group received the same volume of distilled water. The first administration was applied two weeks after the MIA injection.

\subsubsection{Animal sample preparation}

For sample preparation, the rats were anesthetized and a disc ( $2 \mathrm{~mm}$ in diameter) was removed from the unhealthy and healthy cartilage surfaces. The samples were taken under sterile conditions, excess bone and adipose tissue was removed, and only the remaining full thickness cartilage was used for the experiments. The disc was first washed in sterile saline, then stored in $20 \mathrm{ml}$ saline for transportation at room temperature for immediate examination. Before the measurements, all water from the surface was removed. Mean storage time was 4 hours (min: 1 hour, max: 12 hours), all samples were examined the same day of preparation. Preemptive control examinations did not show any changes in the calorimetric properties after storage for 24 hours at $5{ }^{\circ} \mathrm{C}$.

\subsection{Thermal measurements}

The success of the thermal experiments depends on the careful preparation of samples and the judicious selection of the appropriate experimental conditions (such as scanning rate and sample size). In general, DSC samples are analyzed in small metal pans, designed for optimal thermal conductivity and minimum reaction with the samples (for example, aluminum alloy, platinum, stainless steel, or silver) [Clas et al., 1999]. For accurate quantitative work, the thermal mass of the sample and reference pans were matched.

The calorimetric properties of samples were determined by DSC method (Mettler-Toledo DSC 821e apparatus, Mettler-Toledo $\mathrm{GmbH}$, Switzerland). Samples were heated from 0 to 80 ${ }^{\circ} \mathrm{C}$. The heating rate was $0.3{ }^{\circ} \mathrm{C} / \mathrm{min}$. Conventional Hastelloy batch vessels were used with 
$40 \mu \mathrm{l}$ sample volume. All the DSC measurements were preceded in Ar atmosphere, and the flow rate was $100 \mathrm{ml} / \mathrm{min}$. From the DSC curves, the decomposition temperature (onset temperature), the transition temperature range (endset temperature), and the total calorimetric enthalpy change were calculated. Well-defined standards and calibration procedures are particularly important, therefore high care was taken in calibrating the instrument as close to the transition temperatures of interest as possible.

The thermogravimetric analysis was performed with the use of a MOM Derivatograph (MOM, Budapest, Hungary), and the TG, DTG, and DTA curves were determined. The temperature $(\mathrm{T})$ curve shows the linear increase of temperature during the process. DTG curve represents the first derivative of the mass change [Riesen, 1998; Rouquerol, 1989]. Heating was linear from 25 to $150{ }^{\circ} \mathrm{C}$ and the rate of heating was $5{ }^{\circ} \mathrm{C} / \mathrm{min}$. $\mathrm{Al}_{2} \mathrm{O}_{3}$ was used as reference material. In the first step, the total water loss and kinetic parameters were calculated. The kinetic parameters calculated by the derivatograph are the following: the reaction order $(n)$, the activation energy $\left(E_{a}\right)$, and the pre-exponential factor $(A)$ [Arnold et al., 1987].

\subsection{Statistics}

SPSS for Windows statistical program was used to compare enthalpy changes in the different groups. Data are presented as mean, \pm SD, \pm SEM. Statistical significance was assessed by the unpaired two t-test and the level of confidence interval. The results were considered significant, if $\mathrm{p}<0.05$.

\subsection{Ethics}

All tissues were yielded in accordance to legal regulation, international ethical concerns, and patients' consent. The Human Investigation Review Board of the University of Szeged has decided (2006.09.18.) that the experiments comply with the ethics of research and the declaration of the Medical World Federation.

\section{Results}

\subsection{Human hyaline cartilage study}

\subsubsection{Thermogravimetry}

TG, DTG and DTA curves of the normal samples are presented on Fig. 2. Many information can be obtained from the T, TG, DTG and DTA curves. The temperature (T) curve shows the linear increase of temperature during the process.

It was found, that the average total water content of intact (normal) cartilage is $81 \%$, which was probably the interstitial water. To remove the cartilage extracellular water content, 52 $\mathrm{kJ} / \mathrm{M}$ energy was needed.

Total water content of the OA samples was $87 \%$, and $73 \mathrm{~kJ} / \mathrm{M}$ energy was used for the removal of the fluid content (Table 1 and Fig. 3).

Loss of water content in both groups are presented with a sharp step on the TG curve, starting on average temperature of $37^{\circ} \mathrm{C}$ and ending at $116^{\circ} \mathrm{C}$. Linear part of the TG curve begun at around $57^{\circ} \mathrm{C}$ and ended at around $104^{\circ} \mathrm{C}$ (Table 1). Placing a line on this portion of the curve, the slope of the curve can be calculated which represents the speed of the water content loss (Table 2). The slope of the linear region correlated in both groups. 


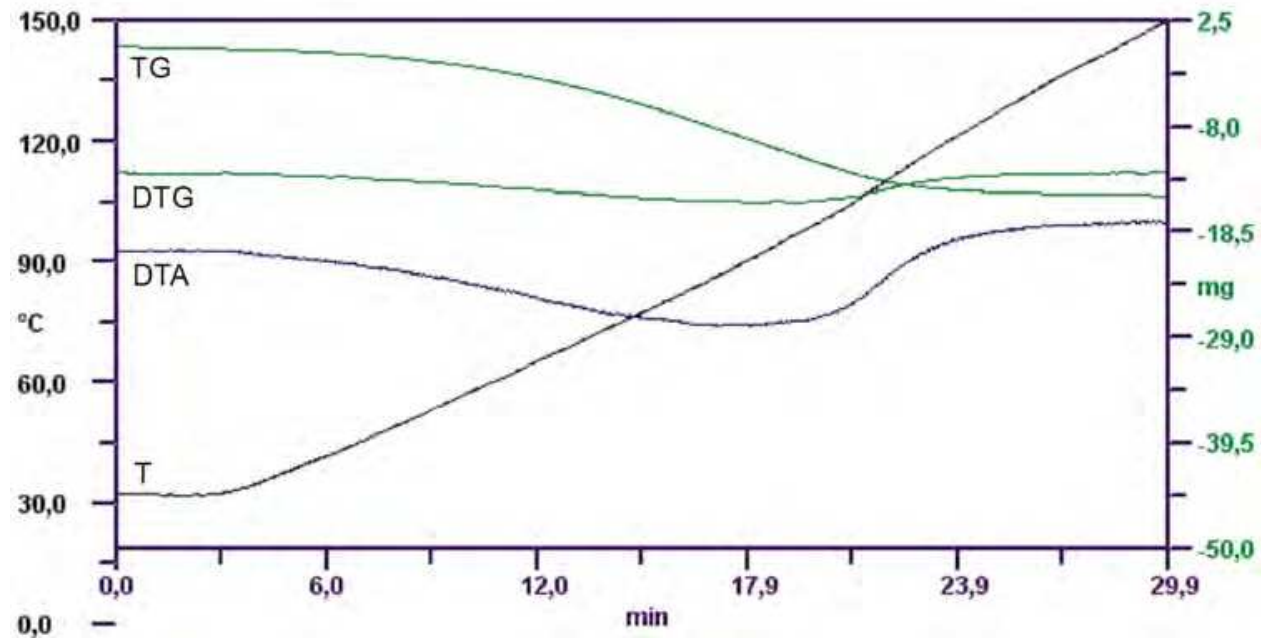

Fig. 2. Thermogravimetric curves of a normal sample

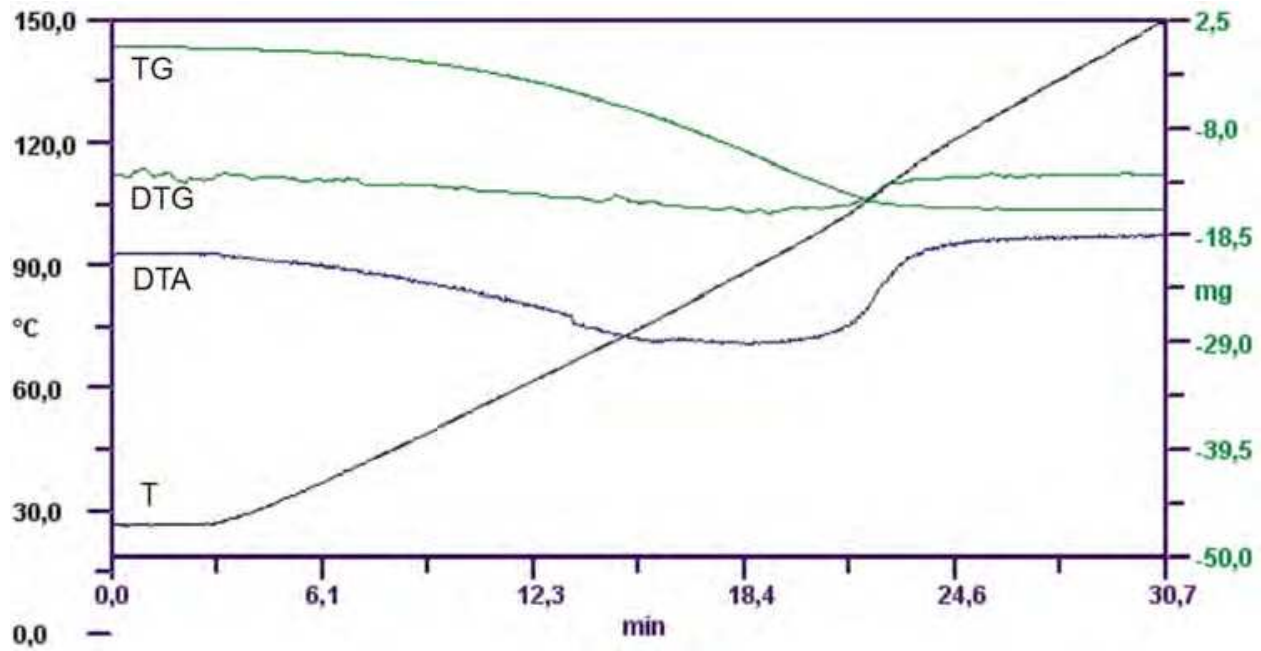

Fig. 3. Thermogravimetric curves of an osteoarthritic sample

\begin{tabular}{|l|l|l|l|l|}
\hline $\begin{array}{l}\text { Sample } \\
\text { group }\end{array}$ & $\begin{array}{l}\text { Sample } \\
\text { number }\end{array}$ & $\begin{array}{l}\text { TG step } \\
\left({ }^{\circ} \mathrm{C}\right)\end{array}$ & $\begin{array}{l}\text { Total mass loss }(\%) \\
(\mathrm{p}=0.05)\end{array}$ & $\begin{array}{l}\mathrm{E}_{\text {act }} \\
(\mathrm{kJ} \mathrm{M}-1)\end{array}$ \\
\hline Normal & 7 & $39.1-113.8$ & $\begin{array}{l}80.79 \\
\text { SD: } 7.09\end{array}$ & $\begin{array}{l}52.33 \\
\text { SD: } 6.68\end{array}$ \\
\hline OA & 16 & $36.4-121.9$ & $\begin{array}{l}86.71 \\
\text { SD: } 7.84\end{array}$ & $\begin{array}{l}72.72 \\
\text { SD: } 23.46\end{array}$ \\
\hline
\end{tabular}

Table 1. Average mass loss and activation energy of normal and degenerated samples. 
In case of the normal hyaline cartilage, $0.196 \mathrm{mg}$ of fluid content release was observed (average mass of the normal samples was $15.48 \mathrm{mg}$ ) with increase of temperature by $1{ }^{\circ} \mathrm{C}$, therefore $1.3 \%{ }^{\circ} \mathrm{C}^{-1}$ loss was detected. In the osteoarthritic samples (average mass: 17.02 $\mathrm{mg}), 0.242 \mathrm{mg}$ decrease was measured which represents $1.4 \%{ }^{\circ} \mathrm{C}-1$ mass reduction. The resulting amount of mass lost in the linear region was recounted from these results (Table 2).

\begin{tabular}{|l|l|l|l|l|l|}
\hline $\begin{array}{l}\text { Sample } \\
\text { Group }\end{array}$ & $\begin{array}{l}\text { Sample } \\
\text { number }\end{array}$ & $\begin{array}{l}\text { TG step linear } \\
\text { region }\left({ }^{\circ} \mathrm{C}\right)\end{array}$ & $\begin{array}{l}\text { Mass loss } \\
(\%)\end{array}$ & Reaction order $(\mathrm{n})$ & $\begin{array}{l}\text { Slope of linear } \\
\text { region }\end{array}$ \\
\hline Normal & 7 & $62.67-102.25$ & -51.45 & $\begin{array}{l}1 \\
\text { SD: } 0.203\end{array}$ & -0.039 \\
\hline OA & 16 & $58.0-104.6$ & -65.24 & $\begin{array}{l}1.03 \\
\text { SD: } 0.27\end{array}$ & -0.048 \\
\hline
\end{tabular}

Table 2. Reaction kinetic parameters of normal and degenerated samples.

\subsubsection{Calorimetry}

With the rise of temperature, an endothermic reaction was observed in all of the cases (Fig. 4). The enthalpy change of the process initiated by the temperature change showed noticeable difference between the normal and pathological groups. (Table 3)

\begin{tabular}{|l|l|l|l|l|l|}
\hline $\begin{array}{l}\text { Sample } \\
\text { group }\end{array}$ & $\begin{array}{l}\text { Sample } \\
\text { number }\end{array}$ & $\begin{array}{l}\Delta \mathrm{H} \\
(\mathrm{J} / \mathrm{g})(-)\end{array}$ & $\begin{array}{l}\text { DSC peak } \\
\left({ }^{\circ} \mathrm{C}\right)\end{array}$ & $\begin{array}{l}\text { Beginning } \\
\left({ }^{\circ} \mathrm{C}\right)\end{array}$ & $\begin{array}{l}\text { Ending } \\
\left({ }^{\circ} \mathrm{C}\right)\end{array}$ \\
\hline Normal & 7 & $\begin{array}{l}788.346 \\
\text { SD: } 83.181\end{array}$ & $\begin{array}{l}50.18 \\
\text { SD: } 3.31\end{array}$ & $\begin{array}{l}\approx 32.5 \\
\text { SD: } 3.45\end{array}$ & $\begin{array}{l}57.09 \\
\text { SD: } 5.35\end{array}$ \\
\hline OA & 16 & $\begin{array}{l}543.838 \\
\text { SD: } 88.572\end{array}$ & $\begin{array}{l}50.34 \\
\text { SD: } 2.937\end{array}$ & $\begin{array}{l}\approx 33.8 \\
\text { SD: } 4.3\end{array}$ & $\begin{array}{l}\approx 33.8 \\
\text { SD: } 4.3\end{array}$ \\
\hline
\end{tabular}

Table 3. Thermal parameters of denaturation (mean $\pm \mathrm{SD}$ ) of normal and degenerated samples.

Greater change in the enthalpy was observed in normal cartilage: $788.346 \mathrm{~J} / \mathrm{g}$ $(\mathrm{SD}=83.18)$. In case of osteoarthritis $543.838 \mathrm{~J} / \mathrm{g}(\mathrm{SD}=88.57)$ was measured (Table 3$)$. Therefore, denaturation caused by heating was larger in the normal human hyaline cartilage. Consequently these samples required the largest amount of energy for decomposition. Statistical tests proved these calculations to be significant (Fisher LSD method, $\mathrm{p}<0.05)$. Denaturation peak in normal cartilage was at $50.18{ }^{\circ} \mathrm{C}(\mathrm{SD}=3.31)$, and it was similar in osteoarthritis $50.34{ }^{\circ} \mathrm{C}(\mathrm{SD}=2.93)$. to that of the control results (Fig. 4). 


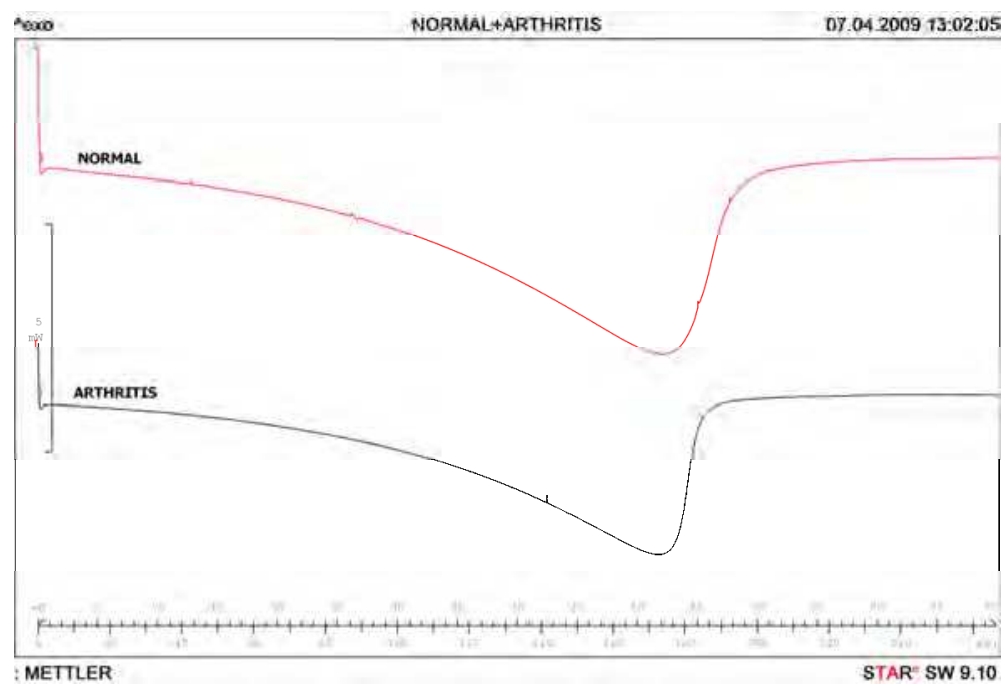

Fig. 4. DSC curve of normal and osteoarthritic human hyaline cartilage samples, the average change in the enthalpy in normal cartilage: $788.346 \mathrm{~J} / \mathrm{g}(\mathrm{SD}=83.18)$ and OA $543.838 \mathrm{~J} / \mathrm{g}$ $(\mathrm{SD}=88.57)$ respectively. (The downwards deflection means endothermic effect)

\subsection{Animal model}

With the rise of temperature an endothermic reaction was observed in all of the cases (Figure 5).

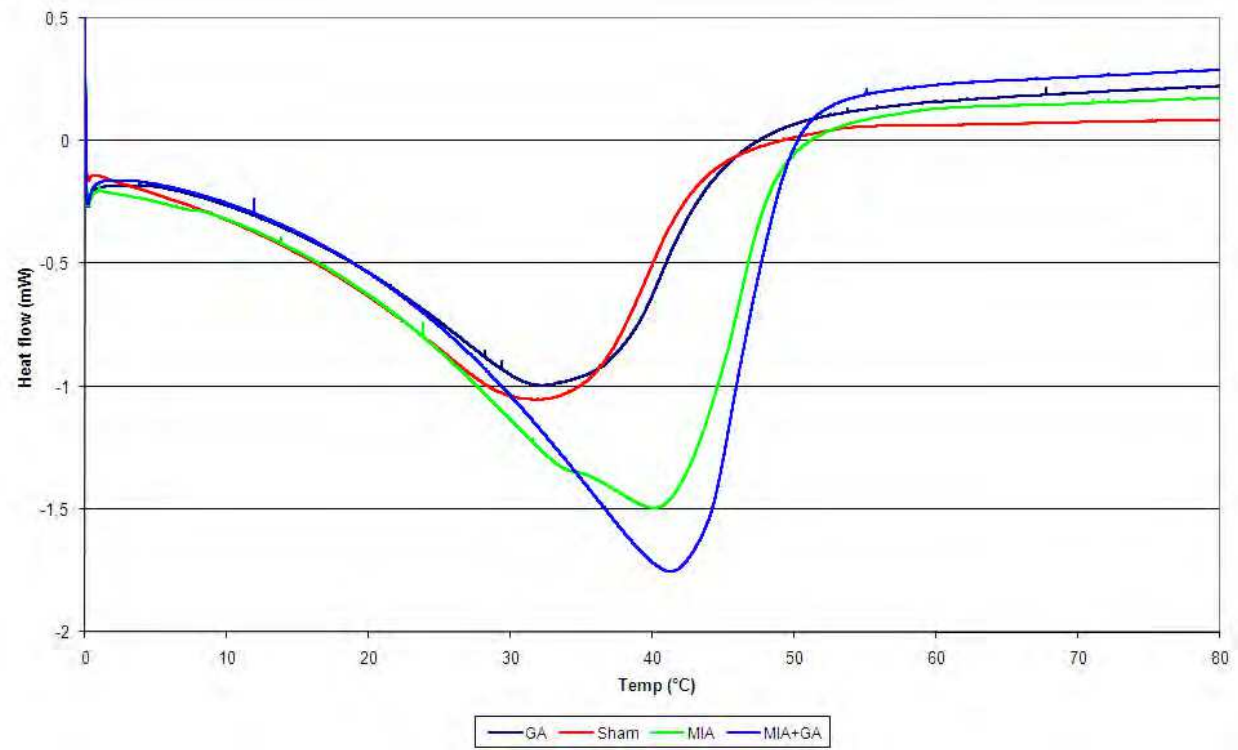

Fig. 5. DSC curve of cartilage samples. (the downwards deflection means endothermic effect) 
The enthalpy change of the process initiated by the temperature change did show marked difference between the normal and pathological groups (Table 4).

\begin{tabular}{|l|l|l|}
\hline $\begin{array}{l}\text { Sample } \\
\text { group }\end{array}$ & $\begin{array}{l}\text { Sample } \\
\text { Number }\end{array}$ & $\begin{array}{l}\Delta \mathrm{H} \\
(\mathrm{kJ} / \mathrm{kg})\end{array}$ \\
\hline Sham & 7 & $\begin{array}{l}-783.65 \\
\text { SD: } 63.44 \\
\text { SEM: } 23.98\end{array}$ \\
\hline \multirow{2}{*}{ GA } & 8 & $\begin{array}{l}-848.86 \\
\text { SD: } 177.53 \\
\text { SEM: } 62.77\end{array}$ \\
\hline & & -1150.19 \\
MIA & & $\begin{array}{l}\text { SD: } 137.63 \\
\text { SEM: } 48.66\end{array}$ \\
\hline & 8 & -1402.92 \\
MIA+GA & & SD: 90.74 \\
SEM: 34.29
\end{tabular}

Table 4. Thermal parameters (mean, $\pm S D, \pm S E M$ ) of all samples

Change in enthalpy was observed in normal cartilage at $-783.65 \mathrm{~kJ} / \mathrm{kg}(\mathrm{SD}=63.44)$, and in case of pre-treatment with Glucosamine-sulphate, a slight increase was seen at $-848.86 \mathrm{~kJ} / \mathrm{kg}$ $(\mathrm{SD}=177.53)$. In the non-treated OA samples (MIA), the change of enthalpy was -1150.19 $\mathrm{kJ} / \mathrm{kg}(\mathrm{SD}=137.63)$. Further increase of the thermal parameters was measured in the OA group that was pre-treated with Glucosamine-sulphate (MIA+GA) $-1402.92 \mathrm{~kJ} / \mathrm{kg}$ (SD = 90.74). Therefore, enthalpy change caused by the loss of water content by heating was lower in the normal samples than in the OA sample groups.

The $\Delta \mathrm{H}$ mean value of the normal samples statistically did not differ significantly from the treated normal group $(p=0.3752)$. On the other hand, statistically extremely significant difference $(p<0.0001)$ was observed when the calorimetric properties of the normal nontreated hyaline samples were evaluated against either the MIA or the MIA+GA groups. (Table 5) Furthermore, even the low end of the confidence interval represents a difference large enough to be considered biologically important.

\begin{tabular}{|l|l|l|}
\hline Compared groups & $95 \%$ confidence interval (from-to) & two-tailed P value \\
\hline Sham/MIA & -489.3105 to -243.7645 & $<0.0001$ \\
\hline Sham/MIA+GA & -710.4533 to -528.0925 & $<0.0001$ \\
\hline MIA/MIA+GA & -385.0286 to -120.4421 & 0.0012 \\
\hline
\end{tabular}

Table 5. Statistical parameters

Further analysis showed additional statistically significant $(\mathrm{p}<0.0012)$ increase in the mean value of the enthalpy change of the non-treated OA group to the treated OA groups. But the size of the confidence interval range difference is inconclusive (Table 5). 


\section{Conclusion}

OA development takes place in consecutive steps of breakdown and attempted regeneration. Though the comprehension about OA has grown enormously over the last years, there is still need to extend our knowledge about the basic context of OA genesis and development. Several biochemical and biomechanical factors are considered for the pathogenesis [Abramson \& Attur, 2009]. The data up to date show, however, that OA is a very complex disease procedure, and it can be speculated, that the context leading to the progressive process is not finally resolved. There might still be molecules involved which have not yet been studied or even identified [Kumar et al., 2001].

$\mathrm{OA}$ is widely believed to result from local mechanical factors acting within the context of systemic susceptibility [Goldring \& Goldring, 2007]. Molecular pathology of osteoarthritis is under intense investigation since biomechanical factors result in chemical alteration within the joint. Rearrangements of intra- and intermolecular bonds in collagen molecule and disaggregation of proteoglycans and their elimination from OA cartilage found to be responsible for water accumulation [Loeuille et al., 2002]. It was also shown that the most part of water is free water and its quantity is increased in the osteoarthritis of the hyaline cartilage [Nikolaeva et al., 2000].

We observed increase in water content of the cartilage matrix in all cases of the investigated degenerative cartilages [Sohár et al., 2007]. Based on our results, it can be stated that water content is higher in impaired samples, meanwhile water interstitial bonding was stronger in these cases. Rise in water adherence was well distinguishable since higher energy was needed for removal. Activation energy correlated considerably with water content in the samples. Denaturation caused by heating was larger in the normal cartilage than in the diseased ones, therefore normal samples required larger amount of energy for decomposition [Tóth et al., 2007].

The purpose of our study was also to clarify the previously reported studies in the literature [Than \& Kereskai, 2005]. By acquiring normal cartilage from live surgery and by performing the investigation in a relatively short period of time compared to the earlier reports [Sohár et al., 2007; Than et al., 2004; Than \& Kereskai, 2005], similar sample environment was provided as with the degenerarative samples. This way, we minimized the extracorpal degeneration. All samples we used showed a clear denaturation peak on the calorimetric curve, therefore volume of the curve was easily calculated giving the enthalpy change of the sample. These changes correlated with the water content of the samples. Due to the increased number of samples acquired for our studies, the results were much better reproducible than results in the literature, and the difference between the normal and diseased samples was significant [Sohár et al., 2007; Tóth et al., 2007].

The newly established thermogravimetric protocol that we used was sufficient for compositional thermoanalytical study of normal and degenerative human hyaline cartilage. Water content elevation contributing to disease progression was observed in OA. Previously, this method has not been used for this type of investigations. The main goal of the thermogravimetric measurements was to identify the nature and quantity of water molecules in the investigated samples. Water molecules' binding mode may have an important consequence in pharmacokinetics. The reaction order turned out to be approximately 1 in all the cases (normal and OA), and the standard deviation was low (Table 2). The TG curve's slope of the linear region showed, that the rate of water loss depends on the water amount remaining in the tissue. Comparing the data in the presented 
tables (Tables 1, 2) (Total mass loss: normal: $80.79 \%$ and OA: $86.71 \%$ ), it can be concluded that the higher water content in the degenerative samples bound stronger to the matrix. However, the reaction order and the slope of the linear region correlated in both groups. This first order kinetic means that the rate of water loss depends on the water amount remaining in the tissue, namely if the amount of water decreases in the tissue, the rate of loss also decreases.

DSC as part of thermal analysis was a reliable method for differentiating normal hyaline cartilage from degenerated samples. The available calorimeter proved to be adequate for these measurements. DSC techniques are still developing and many new variants and applications are reported each year. Combined techniques [Elder, 1994] with microscopic or spectroscopic instruments are of obvious value to the pharmaceutical scientist, although commercially available units are not widely used and have limited pharmaceutical applications. With the rapid development of atomic and molecular scale microscopy, hyphenated micro-thermal analysis techniques, such as atomic force microscopy-DSC, are also becoming commercially available. There may be many future applications of microDSC measurements to pharmaceutical problems, although these are likely to be limited to basic research applications in the next few years until the full potential of the technique has been demonstrated.

Our study has had several limitations, as many other studies on OA. First, the sample size was not large enough to arrive at definitive conclusions. Additional measurements are needed to affirm the results of our study. Secondly, we investigated those patients for normal cartilage samples of the knee, who underwent surgery for the other compartment OA. This was the only ethical and technical way of acquiring normal tissues from living persons for our experiments. Previous thermoanalytical studies used cadaver samples for the investigation as normal human hyaline cartilage. All samples that were extracted for our studies were obtained during live surgeries and were macroscopically intact [Sohár et al., 2007; Tóth et al., 2007]. There is no previous report in the literature of examining normal cartilage from live surgery. Only full thickness cartilage was used for the normal analysis. A new protocol had to be established before the detailed investigation of human tissues could be performed. Most of the known changes in the extracellular matrix in OA come from animal models in the literature since human samples for investigation are not widely available for experiments.

The promise of biomarkers has yet to be fulfilled in OA. Although numerous clinical studies have suggested that specific biomarkers or their combinations can have predictive value in terms of the presence and severity of the disease [Poole, 2003]. The wide variability in these values limits their use for individual patients. Whereas, the use of thermal analysis could be a simple and effective method for controlling the relationship between these markers and disease progression. The revised protocol for sample taking during live surgeries eliminates the presence of disturbing substances during the examination.

Characterization of the altered metabolism in cartilage that promotes disease progression should lead to future treatment options that can prevent structural damage. Since damaged articular cartilage has a very limited potential for healing, prevention is fundamental in treatment. However, prevention is not possible without the knowledge of the basic pathomorphological mechanism leading to cartilage degeneration. With better understanding of the exact amount of water in matrix and its binding characteristics, preventive measures can be developed. These therapeutic steps can be adequately tested 
and monitored with thermal measurements. The use of these methods can also determine the effectiveness of currently used medications (Glucosamin, Chondroitin) for resolving cartilage matrix degeneration.

The results of the experimental OA calorimetric examinations showed that physicochemical properties of normal samples are clearly statistically different from the MIA induced OA groups (treated and non-treated alike). This inequality even at the low end of the 95\% confidence interval represents a difference large enough to be considered biologically important. Therefore, it can be concluded that there is a difference between treatment means and that the variation is large enough to be scientifically relevant. Interestingly the rats injected with monosodium iodoacetate and pretreated with oral glucosamine-sulphate showed significantly higher increase in the value of the enthalpy change than the nontreated, but $\mathrm{OA}$ induced cartilage samples. However, at $95 \%$ confidence interval range (from -385.0286 to -120.4421 ) a strong conclusion can not be drawn. Therefore more data needs to be obtained to draw a clear conclusion.

Further understanding of the initiating events in cartilage destruction, the relationship between the different pathologic influences, and the role of the chondrocyte in maintaining extracellular matrix homeostasis is necessary to reveal potential targets of therapy. Clinical trials are currently underway for a number of potential disease modifying agents that may significantly change the treatment approach for OA. With the use of disease-modifying OA drugs (DMOADs), the necessity for instruments that are sensitive to changes has become very apparent in clinical trials [Qvista, 2008].

\section{Acknowledgment}

Study was supported by „TÁMOP-4.2.1/B-09/1/KONV-2010-0005 - Creating the Center of Excellence at the University of Szeged" is supported by the European Union and cofinanced by the European Regional Development Fund.

We would like to thank the orthopedic surgeon colleagues of the Orthopedic Department, University of Szeged for their gracious support in providing samples for our study from their arthroplasty procedures. We acknowledge laboratory assistants of the Department of Pharmaceutical Technology and the Department of Physiology, University of Szeged for technical assistance.

\section{References}

Abramson, S.B. \& Attur, M. (2009). Developments in the scientific understanding of osteoarthritis. Arthritis Research \& Therapy, 11(3): 227.

Aigner, Z.; Mécs, L.; Sohár, G.; Wellinger, K.; Szabó-Révész, P. \& Tóth, K. (2009). Novel calorimetric investigation of different degenerative disorders of the human hyaline cartilage. J. Thermal Anal. and Calorim., 95(3), 801-804.

Ameye, L.G. \& Young, M.F. (2006). Animal models of osteoarthritis: lessons learned while seeking the "Holy Grail". Current Opinion in Rheumatology, 18 (5), pp. 537-547.

Armstrong, C.G. \& Mow, V.C. (1982). Variations in the intrinsic mechanical properties of human articular cartilage with age, degeneration, and water content. J. Bone Joint. Surg. Am., 64: 88-94. 
Arnold, M.; Somogyvári, P.; Paulik, J. \& Paulik, F. (1987). Derivatograph-C-a microcomputer-controlled simultaneous TG, DTG, DTA, TD and EGA apparatus. J. Therm. Anal., 32: 679-683.

Bagratashvili, V.; Sobol, E.; Sviridov, A.; Popov, V.; Omel'chenko A. \& Howdle, S. (1997). Thermal and diffusion processes in laser-induced stress relaxation and reshaping cartilage. J. Biomech., 30:813-817.

Bihari-Varga, M. Sepulchre, C. \& Moczár, E. (1975). Thermoanalytical studies on proteinpolysaccharide complexes of connective tissues. Journal of Thermal Analysis, 7:675683.

Bihari-Varga, M. (1982). The application of thermoanalytical methods in the investigation of biological substances. J. Therm. Anal., 23:7-13.

Biró, T. \& Bihari-Varga, M. (1972). Thermoanalytical Studies of Tendon Healing. Connective Tissue Res., 1:305-309.

Brandt, K.D.; Radin, E.L.; Dieppe, P.A. \& van de Putte, L. (2006). Yet more evidence that osteoarthritis is not a cartilage disease. Ann. Rheum. Dis., 65, 1261-1264.

Burroughs, P.; Paterson, E. \& Pope, M.I. (1980). Purity determination by differential scanning calorimetry. Anal. Proc., 17: 231-234.

Chae, Y.; Protsenko, D.; Lavernia, E.J. \& Wong, B.J.F. (2009). Effect of water content on enthalpic relaxations in porcine septal cartilage. J. Thermal Anal. and Calorim., 95(3): 937-943.

Clas, S.D.; Dalton, C.R. \& Hancock, B.C. (1999). Differential scanning calorimetry: applications in drug development. Pharm. Sci. Techn. Today, 2: 311-320.

Clegg, D.O.; Reda, D.J.; Harris, C.L.; Klein, M.A.; O'Dell, J.R.; Hooper, M.M.; Bradley, J.D.; Bingham, C.O. 3rd; Weisman, M.H.; Jackson, C.G.; Lane, N.E.; Cush, J.J.; Moreland, L.W.; Schumacher, H.R. Jr.; Oddis, C.V.; Wolfe, F.; Molitor, J.A.; Yocum, D.E.; Schnitzer, T.J.; Furst, D.E.; Sawitzke, A.D.; Shi, H.; Brandt, K.D.; Moskowitz, R.W. \& Williams, H.J. (2006). Glucosamine, chondroitin sulfate, and the two in combination for painful knee osteoarthritis. N Engl J Med., 23;354(8), 795-808.

Collett, L.A.; Brown, M.E. (1998). Biochemical and biological applications of thermal analysis. J. Therm. Anal., 51, 693-726.

Crolle, G. (1980). Glucosamine sulphate for the management of arthrosis: a controlled clinical investigation. D'Este E Curr Med Res Opin., 7(2), 104-9.

Elder, J.P. (1994). Thermophysical characterization studies of pharmaceutical hydrates. Thermochim. Acta,234: 153-164.

Eyre, D. (2002). Collagen of articular cartilage. Arthritis Res., 4: 30-35.

Farkas, T. \& Bihari-Varga, M. \& Biró, T. (1974). Thermoanalytical and histological study of intra-articular papain-induced degradation and repair of rabbit cartilage. I. Immature animals. Ann Rheum Dis., 33:385-390.

Fenton, J.I.; Chlebek-Brown, K.A.; Peters, T.L.; Caron, J.P. \& Orth, M.W. (2000). Glucosamine $\mathrm{HCl}$ reduces equine articular cartilage degradation in explant culture. Osteoarthritis Cartilage, 8(4), 258-65.

Gill, P.S., Sauerbrunn, S.R. \& Crowe, B.S. (1992). High resolution thermogravimetry. J. Therm. Anal., 38: 255-266.

Goldring, M.B. \& Goldring, S.R. (2007). Osteoarthritis. J. Cell. Physiol., 213, 626-634. 
Guingamp, C.; Gegout-Pottie, P.; Philippe, L.; Terlain, B.; Netter, P. \& Gillet, P. (1997). Mono-iodoacetate-induced experimental osteoarthritis: a dose-response study of loss of mobility, morphology, and biochemistry. Arthritis Rheum., 40(9): 1670-9.

Hansen, L.D. \& Russell, D.J. (2006). Which calorimeter is best? A guide for choosing the best calorimeter for a given task. Thermochim. Acta, 450: 71-72.

Hunziker, E. B. (2002). Articular cartilage repair: basic science and clinical progress. A review of the current status and prospects. Osteoarthritis and Cartilage, 10(6), 432-63.

Janusz, M.J.; Hookfin, E.B.; Heitmeyer, S.A.; Woessner, J.F.; Freemont, A.J. \& Hoyland, J.A. (2001). Moderation of iodoacetate-induced experimental osteoarthritis in rats by matrix metalloproteinase inhibitors. Osteoarthritis and Cartililage, 9, 751-60.

Jones, K.J. (1997). The origin and interpretation of the signals of MTDSC. Thermochim. Acta, 304/305: 187-199.

Kalbhen, D.A. (1987). Chemical model of osteoarthritis-a pharmacological evaluation. Rheumatology, 14, 130-1.

Katz, E.P. \& Li, S.T. (1973). The intermolecular space of reconstituted collagen fibrils. J. Mol. Biol., 73:351-369.

Kumar, S.; Connor, J.R.; Dodds, R.A.; Halsey, W.; Van Horn, M.; Mao, J.; Sathe, G.; Mui, P.; Agarwal, P.; Badger, A.M.; Lee, J.C.; Gowen, M. \& Lark, M.W. (2001). Identification and initial characterization of 5000 expressed sequenced tags (ESTs) each from adult human normal and osteoarthritic cartilage cDNA libraries. Osteoarthritis and Cartilage, 9: 641-653.

Loeuille, D.; Olivier, P.; Watrin, A.; Grossin, L.; Gonord, P.; Guillot, G.; Etienne, S.; Blum, A.; Netter, P. \& Gillet, P. (2002). Some biochemical characteristics and water exchange in human articular cartilage in osteoarthrosis. Bull. Exp. Biol. Med., 133, 484-487.

Lorenz, H.; Wenz, W.; Ivancic, M.; Steck, E. \& Richter, W. (2005). Early and stable upregulation of collagen type II, collagen type I and YKL40 expression levels in cartilage during early experimental osteoarthritis occurs independent of joint location and histological grading. Arthritis Res. Ther., 7(1), R156-165.

Mankin, H.J. \& Thrasher, A.Z. (1975) Water content and binding in normal and osteoarthritic human cartilage. J. Bone Joint. Surg. Am., 57: 76-80.

Maroudas, A. \& Schneiderman, R. (1987). "Free" and "Exchangeable" or "Trapped" and "Non-exchangeable" Water in Cartilage. J. of Orthop. Res., 5:133-138.

Mayne, R. (1989). Cartilage collagens. What is their function, and are they involved in articular disease? Arthritis Rheum., 32: 241-246.

McAlindon, T. (2003). Why are clinical trials of glucosamine no longer uniformly positive? Rheum Dis Clin N Am, 29 789-801.

Mécs, L.; Aigner, Z.; Sohár, G.; Szabó-Révész, P. \& Tóth, K. (2009). Characterization of human cartilage in degenerated spine disease with differntial scanning calorimetry. J. Thermal Anal. and Calorim., 95(3), 809-811.

Melchior, D.L. \& Steim, J.M. (1976). Thermotropic Transitions in Biomembranes Ann. Rev. Biophys. Bioeng., 5:205-238.

Mkukuma, L.D.; Imrie, C.T.; Skakle, J.M.S.; Hukins, D.W.L. \& Aspden, R.M. (2005). Thermal stability and structure of cancellous bone mineral from the femoral head of patients with Osteoarthritis or osteoporosis. Ann Rheum Dis., 64:222-225.

Nikolaeva, S.S.; Chkhol, K.Z.; Bykov, V.A.; Roshchina, A.A.; Iakovleva, L.V.; Koroleva, O.A.; Omel'ianenko, N.P. \& Rebrov, L.B. (2000). Water-exchange processes in hyaline 
cartilage and its basic components in a normal state and in osteoarthritis. Vopr. Med. Khim., 6, 81-90.

Oegema, Jr.; Deloria, L.B.; Sandy, J.D. \& Hart, D.A. (2002). Effect of oral glucosamine on cartilage and meniscus in normal and chymopapain-injected knees of young rabbits. Arthritis $\mathcal{E}$ Rheumatism, 46 (9), pp. 2495-2503.

O'Neill, M.J. (1964). The analysis of a temperature-controlled scanning calorimeter. Anal. Chem., 36: 1238-1245.

Park, S.; Krishnan, R.; Nicoll, S.B. \& Ateshian, G.A. (2003). Cartilage interstitial fluid load support in unconfined compression. J. Biomechanics,36: 1785-1796.

Paulik, F.; Paulik, J. \& Erdey, L. (1958). Der Derivatograph - I. Mitteilung Ein automatisch registrierender Apparat zur gleichzeitigen Ausführung der Differentialthermoanalyse, der thermogravimetrischen und der derivativthermogravimetrischen Untersuchungen. Fresenius' Zeitschrift für Analytische Chemie., 160:241-252.

Poole, A. (2003). Biochemical/immunochemical biomarkers of osteoarthritis: utility for prediction of incident or progressive osteoarthritis. Rheumatic Disease Clinics of North America, 29: 803-818.

Pritzker, K.P.H.; Gay, S.; Jimenez, S.A.; Ostergaard, K.; Pelletier, J.P.; Revell, P.A.; Salter, D. \& van den Berg, W.B. (2006). Osteoarthritis cartilage histopathology: grading and staging. Osteoarthritis and Cartilage, 14: 13-29.

Privalovand, P.L.\& Plotnikov, V.V. (1989). Three generations of scanning microcalorimeters for liquids. Thermochim. Acta., 139:257-277.

Qvista, P.; Bay-Jensena, A.C.; Christiansena, C.; Erik, B.D.; Pastoureaub, P. \& Morten, A.K. (2008). The disease modifying osteoarthritis drug (DMOAD): Is it in the horizon? Pharm. Res., 58, 1-7.

Reginster, J.Y. (2001). Long-term effects of glucosamine sulphate on osteoarthritis progression: a randomised, placebo-controlled clinical trial. The Lancet, 357, 251-256.

Richardson, M.J. (1997). Quantitative aspects of differential scanning calorimetry. Thermochim. Acta, 300: 15-28.

Riesen, R. (1998). Adjustment of heating rate for maximum resolution in TG and TMA (MaxRes). J. Therm. Anal. 53: 365-374.

Rouquerol, J. (1989). Controlled transformation rate thermal analysis: The hidden face of thermal analysis. Thermochim. Acta, 144: 209-224.

Sandell, L.J. \& Hering, T.M. (2001) Biochemistry and molecular and cell biology of articular cartilage in osteoarthritis. In: Osteoarthritis. Diagnosis and medical/surgical management, Moskowitz, R.W.; Howell, D.S.; Altman, R.D. Buckwalter, J.A. Goldberg, V.M. pp. 115-143, WB Sauders Company, Philadelphia.

Simon, J.; Bihari-Varga, M.; Erdey, L. \& Gerő, S. (1969). Thermal investigations on structural glycosaminoglycans and proteins. 1. The influence of age on the thermal decomposition of aortic intima. Acta Biochim. Biophys. Acad. Sci. Hung., 3:273-278.

Sohár, G.; Pallagi, E.; Szabó-Révész, P. \& Tóth, K. (2007). New thermogravimetric protocol for the investigation of normal and damaged human hyaline cartilage. J. Therm. Anal. Cal., 89: 853-856.

Soltz, M.A. \& Ateshian, G.A. (1998). Experimental verification and theoretical prediction of cartilage interstitial fluid pressurization at an impermeable contact interface in confined compression. J. Biomechanics, 31: 927-934. 
Than, P.; Domán, I. \& Lórinczy, D. (2004). Differential scanning calorimetry in the research of degenerative musculoskeletal disorders. Thermochim. Acta, 415: 83-87.

Than, P. \& Kereskai, L. (2005). Thermal analysis of the osteoarthritic human hyaline cartilage. J. Therm. Anal. Cal., 82: 213-216.

Than, P.; Vermes, C.; Schäffer, B. \& Lőrinczy, D. (2000). Differential scanning calorimetric examination of the human hyaline cartilage. A preliminary study. Thermochim. Acta, 346: 147-151.

Than, P. \& Lörinczy, D. (2003). Differential scanning calorimetric examination of the osteoarthritic hyaline cartilage in rabbits. Thermochim. Acta, 404, 149-153.

Tóth, K., Sohár, G., Pallagi, E. \& Szabó-Révész, P. (2007). Further characterization of degenerated human cartilage with differential scanning calorimetry. Thermochim. Acta, 464: 75-77.

Tóth, K.; Sohár, G.; Aigner, Z.; Greksa, F. \& Szabó-Révész, P. (2009). Novel Calorimetric properties of human cartilage samples in rheumatoid arthritis. J. Thermal Anal. and Calorim., 95(3), 813-815.

van den Berg, W.B. (2001). Lessons from animal models of osteoarthritis. Current Opinion in Rheumatology, 13 (5), pp. 452-456.

Vlad, S.C.; LaValley, M.P.; McAlindon, T.E. \& Felson, D.T. (2007) Glucosamine for pain in osteoarthritis: why do trial results differ? Arthritis Rheum., 56(7), 2267-77. Review.

Wiegand, N.; Vámhidy, L.; Kereskai, L. \& Lőrinczy, D. (2010). Differential scanning calorimetric examination of the ruptured Achilles tendon in human. Thermochimica Acta, 498. 7-10.

Wiegand, N.; Vámhidy, L.; Patczai, B.; Dömse, E.; Kereskai, L. \& Lőrinczy, D. (2009). Differential scanning calorimetric examination of the human skeletal muscle in a compartment syndrome of the lower extremities. J. Thermal Anal. Calorim., 98, 177182.

Zhang, W.; Moskowitz, R.W.; Nuki, G.; Abramson, S.; Altman, R.D.; Arden, N.; BiermaZeinstra, S.; Brandt, K.D.; Croft, P.; Doherty, M.; Dougados, M.; Hochberg, M.; Hunter, D.J.; Kwoh, K.; Lohmander, L.S. \& Tugwell, P. (2008). OARSI recommendations for the management of hip and knee osteoarthritis, Part II: OARSI evidence-based, expert consensus guidelines. Osteoarthritis Cartilage, 16(2), 137-62. 


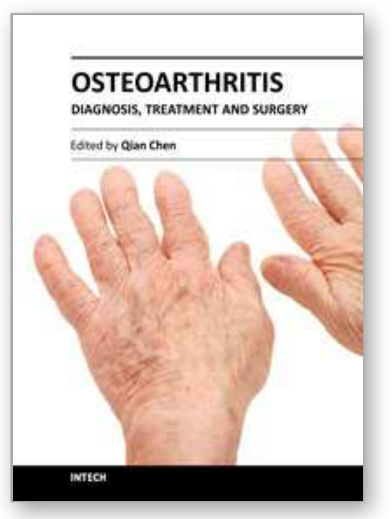

\author{
Osteoarthritis - Diagnosis, Treatment and Surgery \\ Edited by Prof. Qian Chen
}

ISBN 978-953-51-0168-0

Hard cover, 404 pages

Publisher InTech

Published online 02, March, 2012

Published in print edition March, 2012

Osteoarthritis is one of the most debilitating diseases affecting millions of people worldwide. However, there is no FDA approved disease modifying drug specifically for OA. Surgery remains an effective last resort to restore the function of the joints. As the aging populations increase worldwide, the number of OA patients increases dramatically in recent years and is expected to increase in many years to come. This is a book that summarizes recent advance in OA diagnosis, treatment, and surgery. It includes wide ranging topics from the cutting edge gene therapy to alternative medicine. Such multifaceted approaches are necessary to develop novel and effective therapy to cure OA in the future. In this book, different surgical methods are described to restore the function of the joints. In addition, various treatment options are presented, mainly to reduce the pain and enhance the life quality of the OA patients.

\title{
How to reference
}

In order to correctly reference this scholarly work, feel free to copy and paste the following:

Gellért Sohár, Piroska Szabó-Révész, Kálmán Tóth and Zoltán Aigner (2012). Characterization of Live and Experimentally Degenerated Hyaline Cartilage with Thermal Analysis, Osteoarthritis - Diagnosis, Treatment and Surgery, Prof. Qian Chen (Ed.), ISBN: 978-953-51-0168-0, InTech, Available from:

http://www.intechopen.com/books/osteoarthritis-diagnosis-treatment-and-surgery/characterization-of-live-andexperimentally-degenerated-hyaline-cartilage-with-thermal-analysis

\section{INTECH}

open science | open minds

\author{
InTech Europe \\ University Campus STeP Ri \\ Slavka Krautzeka 83/A \\ 51000 Rijeka, Croatia \\ Phone: +385 (51) 770447 \\ Fax: +385 (51) 686166 \\ www.intechopen.com
}

\author{
InTech China \\ Unit 405, Office Block, Hotel Equatorial Shanghai \\ No.65, Yan An Road (West), Shanghai, 200040, China \\ 中国上海市延安西路65号上海国际贵都大饭店办公楼 405 单元 \\ Phone: +86-21-62489820 \\ Fax: $+86-21-62489821$
}


(C) 2012 The Author(s). Licensee IntechOpen. This is an open access article distributed under the terms of the Creative Commons Attribution 3.0 License, which permits unrestricted use, distribution, and reproduction in any medium, provided the original work is properly cited. 